\section{TODAY'S RADIO TELESCOPES}

Radioastronomical Methods of Antenna Measurements By A. D. Kuz'min and A. E. Salomonovich. Translated by K. N. Trirogoff. Translation edited by Ernest Jacobs. (Electrical Science: a Series of Monographs and Texts.) Pp. xvi + 182. (New York: Academic Press, Inc.; London: Academic Press, Inc. (London), Ltd., 1966.) $\$ 8 \cdot 50$.

THE past ten years have witnessed an impressive growth of new telescopes which can explore the Universe by radio and radar. One of the earliest of this generation of radio telescopes, the $250 \mathrm{ft}$. diameter Mark I at Jodrell Bank, has now completed ten years of service in planetary, galactic and extragalactic studies. It has since been joined by an international group of large fully or partially steerable telescopes including the $210 \mathrm{ft}$. at Parkes, Australia, the $300 \mathrm{ft}$. at Greenbank, USA, the $1,000 \mathrm{ft}$. in Aricebo, Puerto Rico, and the $660 \mathrm{ft} . \times 130 \mathrm{ft}$. tiltable plane mirror at Nançay, France. A new generation of telescopes capable of operating at very short wavelengths ( $2 \mathrm{~cm}$ or even shorter) has been put into service during the past two years. Three such instruments $140-150 \mathrm{ft}$. in diameter have been installed in eastern USA and Canada and already have been able to satisfy an upsurge of interest in the short wavelength emission from quasars and other compact radio galaxies and in the structure of galactic ionized hydrogen regions seen both in their continuum emission and in their recombination line emission. Other large telescopes have been built by Russia and USA for tracking deep-space probes.

Unfilled aperture teleseopes with large spacings of their component collecting areas, and consequently higher resolution than the filled aperture telescopes, have also been developed during this period. These include the 1 mile synthesis telescope at Cambridge, the 1 mile cross telescope at Molongo, Australia, and the 1.9 mile diameter ring telescope at Culgoora, Australia.

Radio astronomy is an integral part of the broad front of astronomy and has provided a strong impetus to many branches of the subject, particularly galactic structure and topics relating to cosmology. The quest for more sensitive and versatile telescopes to pursue these studies continues. The Dutch are well on the way towards completing an ambitious synthesis system at Westerbork, while the German radio astronomers are preparing to build a $330 \mathrm{ft}$. fully steerable telescope near Bonn with a grant from the Volkswagen Foundation. In Great Britain a move has been made towards the construction of a $400 \mathrm{ft}$. telescope to operate at wavelengths down to $20 \mathrm{~cm}$ or shorter when the Science Research Council decided to negotiate a contract for a final design study. American radio astronomers have been given support by the Dicke committee of the National Science Foundation in their request for a large synthesis system consisting of eight $130 \mathrm{ft}$. telescopes and for the resurfacing of the $1,000 \mathrm{ft}$. Aricebo telescope to enable it to work down to $10 \mathrm{~cm}$ wavelengths.

An important part of the commissioning procedure for any new telescope is the accurate calibration of the position of its electrical axis and of the telescope gain at various wavelengths. The book Radioastronomical Methods of Antenna Measurements by A. D. Kuz'min and A. E. Salomonovich provides the background for such measurements. These two radio astronomers from the Lebedev Physical Institute, Moscow, have first hand experience in this field with their $72 \mathrm{ft}$. telescope which has a good performance at wavelengths down to $8 \mathrm{~mm}$. They discuss in detail the basic concepts of receiver design and calibration in addition to those of aerial gain measurement. Their troatment, which is rigorous throughout, also includes an estimate of the effects of atmospheric refraction and absorption, the effects of finite time constant and beam width on the measurement of radio sources.
A useful parameter in evaluating the performance of the combined aerial and receiver system when used to detect weak signals as in radio astronomy or communications operations is the ratio of aerial gain to system noise figure. This concept, which is hinted at in the book, underlines the compromise which has to be struck between highest aerial gain of a given reflector and the consequent contribution to system noise by the aerial spillover. With the advent of high performance low noise receivers operating at a few tens of degrees Kelvin input noise temperatures, this parameter is a fundamental factor in aerial design.

This book has concentrated entirely on the calibration of filled aperture radio telescopes and has shown how radio sources can be used for this purpose. There are related problems in setting up and calibrating non-filled aperture telescopes. These instruments provide the ultimate in accurate angular location. Now that very long baseline interferometers have been successfully established the process can be inverted to derive the interferometer baseline to a fraction of a wavelength from astronomical observations. These measurements could be of geophysical importanee.

The translators have performed a valuable service in making this excellent book available in the English language. They have included many explanatory footnotes to the text. There are, however, traces of literal translation in some passages as well as many typographical errors in the text, including a misleading factor of $10^{2}$ in Table 4 which gives the flux density of radio sources suggested for calibration purposes. These are not major blemishes in a book which will be found useful to those working in radio astronomy and in communications systems.

R. D. Davies

\section{ENGLISH FOR GERMANS}

Dictionary of Science and Technology, English-German Compiled and arranged by A. F. Dorian. With the co-operation of L. Herzbruch. Pp. 1,238. (Amsterdam, London and New York: Eisevier Publishing Company, 1967.) $180 s$.

THIs English-German dictionary which, so the blurb says, includes reference to the most important terms from 128 different fields of science and techrology, should be very useful to anyone having to translate technical English into German. The German scientist reading a vitally important English paper, if he does not speak English already, which he probably does, should be pleased to have recourse to this single volume covering all branches of physical and biological science. So should the translator busy rendering complex scientific English prose into German, or anyone else who needs to know the German equivalent of the many words which fill the seven centimetres between the covers of this book.

Each word has an explanation of the branch of science from which it comes, together with its translation; for example : tranquillizer [med] Beruhigungsmittel $n$; rudderhole [naut] Ruderstocköffnung $f$; hidradenitis [med] Schweissdrüsenentzündung $f$. There are also often explanations of the meaning of the words; for example: mind [gen] (abstract term for any form of collective intelligence) Sinn $m$, Gemüt $n$; hexachloroethane [chem] (a rubber accelerator and camphor substitute in celluloid manufacture) Hexachloräthan $n$, Perchloräthan $n$. These explanations might be of more use to readers if they were in German; after all, the English translator is more likely to know what the English words mean than is the German scientist to be able to understand the explanation.

Revised and enlarged editions of the dictionary are to follow every eight years to keep the work up to date, and the German-English volume will appear this year to $\mathrm{ccm}$. plete a useful set.
MARY LiNDLEY 